\title{
FUNÇÃO DAS ARISTAS SOBRE CARACTERÍSTICAS DA SEMENTE DE TRIGO
}

\section{Diógenes Cecchin Silveira \& Luiz Pedro Bonetti²;}

${ }^{1}$ Acadêmico do curso de Agronomia, Bolsista PIBIC/UNICRUZ da Universidade de Cruz Alta - Unicruz (diogenessilveira@hotmail.com) Cruz Alta- RS, Brasil.

${ }^{2}$ Professor MSc da Universidade de Cruz Alta - Unicruz (Ibonetti@unicruz.edu.br) Cruz AltaRS, Brasil.

Recebido em: 15/07/2016 - Aprovado em: 29/07/2016 - Publicado em: 31/08/2016 DOI: 10.18677/Agrarian_Academy_2016_004

O propósito do presente estudo foi determinar a influência da presença de aristas em espigas de trigo sobre a qualidade fisiológica das sementes, e seu efeito sobre características de grãos e plântulas, produzidos sob condições de campo na região noroeste do Rio Grande do Sul. O experimento foi conduzido na Área Experimental do Curso de Agronomia da Unicruz, em Cruz Alta, região noroeste do Rio Grande do Sul, em solo Latossolo Vermelho Distrófico, em delineamento experimental de blocos ao acaso. Foram avaliados quatro tratamentos: com arista, sem arista, remoção de $100 \%$ das aristas e remoção de $50 \%$ das aristas. Genótipos de trigo aristados apresentaram peso de mil sementes superior aos genótipos de trigos não aristados ou com remoção da arista.

PALAVRAS-CHAVE: Atividade fotossintética, rendimento, peso de grãos.

\section{FUNCTION OF THE AWNS ON CHARACTERISTICS OF WHEAT SEED}

\begin{abstract}
The purpose of this study was to determine the influence of the presence of awns in wheat ears on the physiological seed quality, and its effect on some grain characteristics and seedlings produced under field conditions in the northwest of Rio Grande Sul State. The experiment was conducted at the Experimental Field of the University of Cruz Alta Agronomy Course, Cruz Alta, northwestern region of Rio Grande do Sul, in soil Oxisoil. The experimental design was a randomized block design with plots of four rows of $5 \mathrm{~m}$ long, $\mathrm{cm}$ spacing of $0,17 \mathrm{~m}$ and six replications. Four treatments were evaluated: with awn, without awn, removal of $100 \%$ of the awns and removing $50 \%$ of the awns. The results showed that awned wheat genotypes have thousand seed weight superior to awnless wheat genotypes or genotypes with removal of awns.
\end{abstract}

KEYWORDS: Photosynthetic Activity, yield, grain weight.

\section{INTRODUÇÃO}

O trigo é o segundo cereal mais produzido no mundo sendo utilizado de diversas formas, desde a farinha para a panificação, no farelo usado na alimentação animal, entre outros aproveitamentos industriais (CALDEIRA et al., 2003). Na região Sul do Brasil o cultivo desse cereal é de extrema importância para a sustentabilidade 
de pequenas e médias propriedades, estando altamente integrado em esquemas de rotação/sucessão com as culturas da soja e do milho no sistema de plantio direto (VALÉRIO et al., 2009). De acordo com SILVA et al., (2002) é a cultura de inverno que possui a maior importância econômica, sendo cultivado sob as mais diversas condições de ambiente, apresentando boa produtividade de grãos, grande potencial de qualidade nutricional e elevado grau de adaptabilidade.

Conforme a Companhia Nacional de Abastecimento (CONAB, 2014), a região Sul é a principal produtora de trigo do país. Segundo FELICIO et al., (2000) o clima favorável para o trigo deve apresentar inverno suave, com alta radiação solar, sem chuvas fortes e suprimento de água fornecido pela umidade armazenada no solo.

Já no que diz respeito aos produtos da fotossíntese, estes elaborados nas folhas situadas na porção superior do colmo, principalmente na folha bandeira e nas aristas são responsáveis pela maior parte da produção (DOMICIANO et al., 2009). A maior disponibilidade de assimilados próximos a antese pode representar mais flores férteis e, consequentemente, grãos em maior número e tamanho, com maior capacidade de formar grãos cheios (RODRIGUES, 2000; SILVA et al., 2003).

Novas oportunidades estão sendo exploradas para um melhor desempenho do trigo em ambientes limitados de água, de acordo com variação genotípica no crescimento da parte aérea se torna melhor compreendida para implantação e seleção em programas de melhoramento (MAYDUO et al., 2014). De acordo com SANCHEZ-BRAGADO et al., (2014), o interesse é crescente no papel da espiga para apoiar a assimilação de carbono na parte superior da planta.

Durante o período de enchimento de grãos, as aristas, folha bandeira e folhas da posição apical da planta são órgãos fotossintéticos potencialmente eficientes em termos de produção na cultura do trigo (MAHMOOD \& CHOWDHRY, 1997). As aristas localizam-se próximas aos grãos, e tem grande parte de sua atividade fotossintética, extremamente elevada. Além disso, a mesma tem uma característica xeromórfica, sendo assim, pode ser órgão fotossintético durante períodos de estresse hídrico, segundo WEYRICH et al. (1995) e compensam a redução da fotossíntese pela folha bandeira, durante o período em que esta é subordinada a estresse (GENEC, 1977). Além disso, segundo LOPEZ-CASTAÑEDA et al., (2014) a contribuição potencial da espiga poderia ser grande com espigas aristadas, interceptando entre $18 \%$ e $45 \%$ da radiação incidente durante o período de enchimento de grão dependendo do genótipo.

Um grande número de pesquisas sobre a correlação entre rendimento e presença de aristas têm sido revisto na literatura, sendo que a maioria dos pesquisadores crê que as aristas proporcionam mais altos rendimentos e grãos mais cheios, do que genótipos que não possuem aristas (MILLER \& GAUCH, 1944; VERVELDE, 1953). Ainda, REYNOLDS \& TUBEROSA (2008) cita que aristas mais compridas são consideradas como uma característica importante como componente em ideótipos de trigos de alto rendimento, em particular para o trigo cultivado sob condições de deficiência hídrica.

MOTZO \& GIUNTA (2002) avaliaram o efeito sobre o rendimento de grãos devido a aumento da capacidade fotossintética de espigas com aristas, em estudo com linhagens isogênicas aristadas e múticas de trigo duro (Triticum durum). Esses autores constataram que as aristas promoveram um aumento de superfície da área de espigas na ordem de 36 a 59\%, dependendo do comprimento que variou numa média de 5,6 a $13,8 \mathrm{~cm}$. Isto teria resultado numa média de $4 \%$ a mais de interceptação de radiação por parte das espigas com aristas. Nesse estudo, realizado em Sardinia, na Itália, durante três anos, as aristas tiveram efeito positivo 
sobre o rendimento de grãos de trigo duro, na média de dois anos, de 10 e 16\%, respectivamente. Já em outras plantas, como a cevada, de acordo com SCOTT \& DENNIS-JONES (1976), a posição das aristas na planta, facilita a interceptação da radiação solar e, quase sempre, a superfície é equivalente à de uma folha.

Diante desses argumentos, o propósito do presente estudo foi determinar a influência da presença de aristas em espigas de trigo sobre a qualidade fisiológica das sementes, e o efeito sobre características de grãos e plântulas, produzidos sob condições de campo na região noroeste do Rio Grande do Sul.

\section{MATERIAL E METODOS}

O presente experimento foi dirigido na Área Experimental do Curso de Agronomia da Unicruz, em Cruz Alta, situada no noroeste do Rio Grande do Sul, com altitude de 450m, latitude de 2833'47,09" S e longitude de 53937'22,49" W, localizada em solo classificado como Latossolo Vermelho Distrófico. A área experimental encontra-se em condições climáticas caracterizadas por Koppen para o estado do Rio Grande do Sul, sendo como clima do tipo "Cfa". A distribuição média mensal de precipitações ocorrida durante a execução do experimento encontra-se graficamente quantificada na Figura 1. As temperaturas apresentam grandes variações sazonais, possuindo verões quentes e invernos rigorosos, com ocorrência de geada e eventual precipitação.

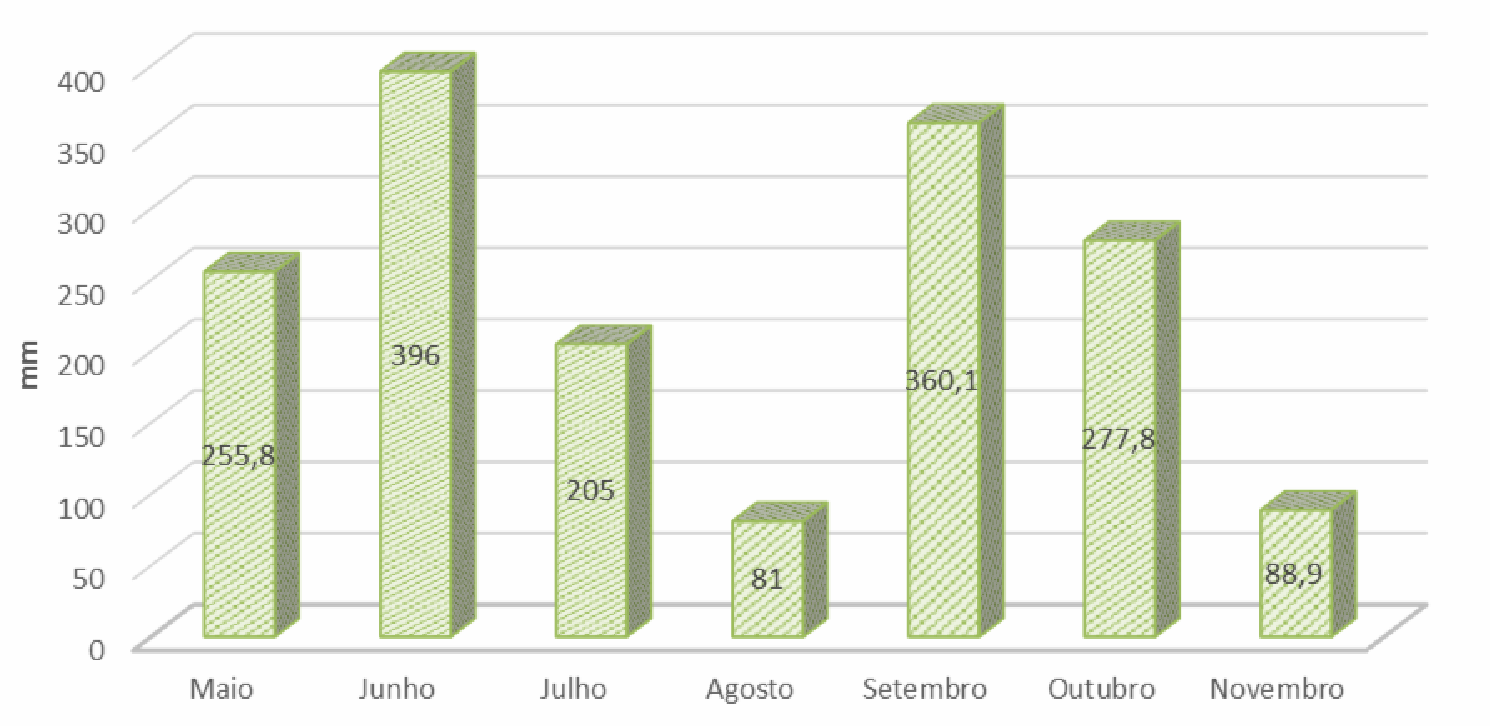

FIGURA 1-Precipitação média mensal durante o período de condução do experimento.

O delineamento experimental foi $\mathrm{o}$ de blocos ao acaso com parcelas constituídas de quatro fileiras de $5 \mathrm{~m}$ de comprimento, com espaçamento de $0,17 \mathrm{~m}$ e seis repetições. Foram avaliados quatro tratamentos: com arista, sem arista, remoção de $100 \%$ das aristas e remoção de $50 \%$ das aristas. A remoção total das aristas foi promovida através de cortes das mesmas rente ao ponto de inserção na espiga. Já a remoção parcial foi feita pelo corte na porção mediana da arista. Os cortes foram efetuados mecanicamente através da utilização de uma tesoura.

A densidade de semeadura utilizada foi de 330 sementes viáveis por $\mathrm{m}^{2}$. A semeadura foi efetuada no dia 09/06/2014, sendo a adubação utilizada de $250 \mathrm{~kg} / \mathrm{ha}$ da fórmula 5-25-25, a colheita foi realizada no dia 12/11/2014. 
Para avaliação foram coletadas 30 espigas por parcela, ao acaso, de cada tratamento, sendo determinado como parâmetros avaliativos o peso de mil sementes (PMS), germinação (\%), biomassa verde de plântula (BVP) e biomassa seca de plântula (BSP). Os resultados obtidos foram submetidos a análise da variância pelo teste de Tukey, a $5 \%$ de probabilidade.

\section{RESULTADOS E DISCUSSÕES}

Os dados médios do peso de mil sementes (PMS), germinação (em \%), biomassa verde por plântula (BVP) e biomassa seca por plântula (BSP) encontramse detalhados na Tabela 1. Os resultados contidos na tabela 1 indicaram que o peso médio de mil sementes do genótipo aristado foi superior ao do genótipo mútico, o que pode ser atribuído ao fato de ambos serem materiais genéticos diferentes.

No entanto, quando se compara o peso médio de mil sementes produzidas em espigas com remoção total de aristas a de espigas com remoção parcial de aristas, ambas do mesmo genótipo, pode-se constatar que houve diferença significativa $(16,4 \mathrm{~g}$ e $18,3 \mathrm{~g})$ respectivamente. Indo de acordo com o consenso geral é de que a vantagem dos trigos aristados é maior em condições climáticas áridas e semiáridas (MILLER \& GAUCH, 1944; VERVELDE, 1953; GRUNDBACHER, 1963).

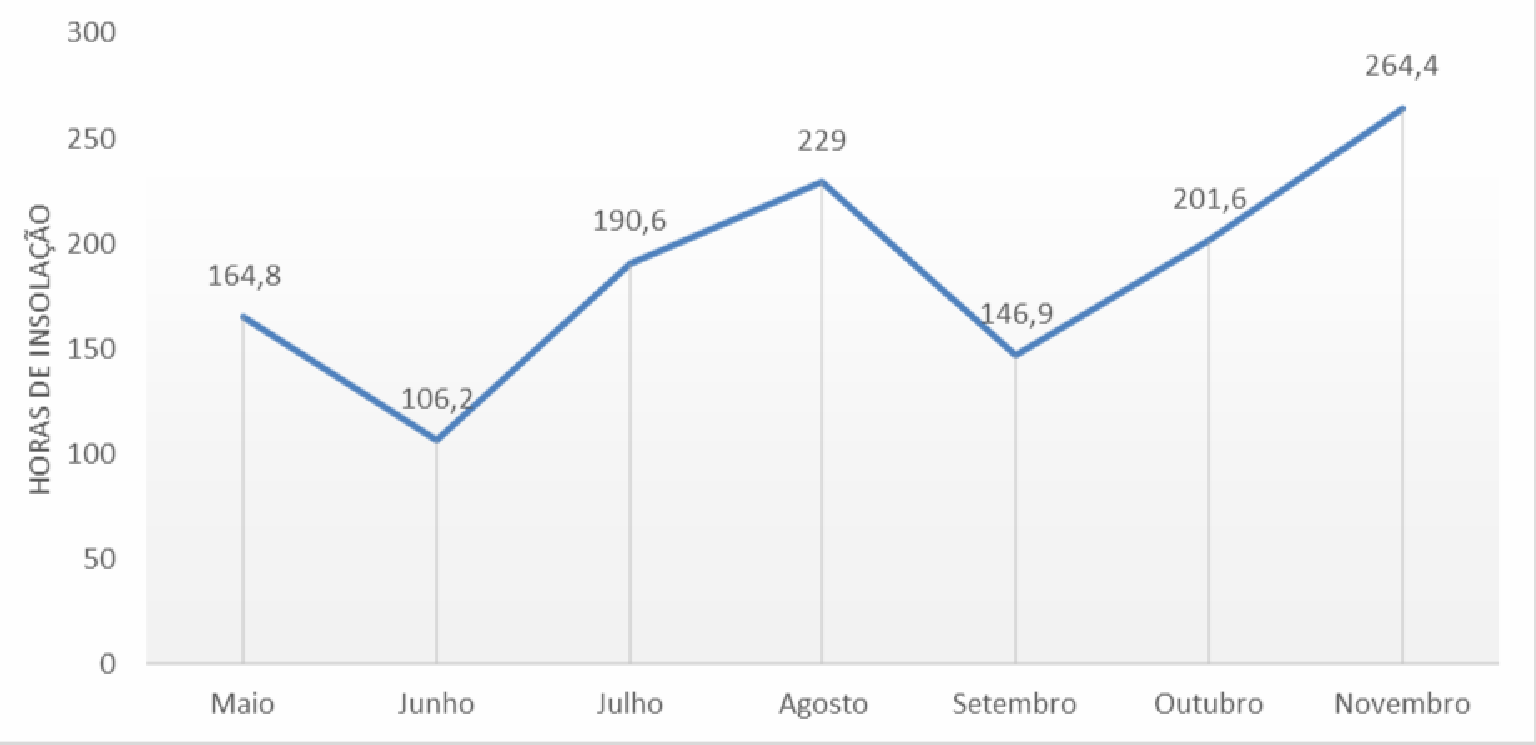

FIGURA 2-Número médio mensal de horas de insolação durante a condução do experimento.

No que diz respeito à insolação, o número médio mensal de horas de sol mais elevado coincidiu com o fim do período correspondente ao estádio reprodutivo das plantas de trigo que participaram do presente estudo. Nesse período, restavam verdes - e fotossinteticamente ativas - apenas as aristas, enquanto os demais órgãos (colmos, folhas, folhas bandeira e espigas) já se encontravam secos (Figura 2). A esse respeito, GUARIENTI et al. (2003), avaliando o efeito de variáveis meteorológicas na qualidade industrial e rendimentos de grãos de trigo, verificaram que a radiação solar global influenciou positivamente o peso do hectolitro, peso de mil grãos, força geral de glúten e o rendimento.

O percentual de germinação mostrou-se superior para o genótipo com remoção parcial (86\%), seguido do genótipo aristado (84\%), sobre o genótipo mútico $(68 \%)$ ou com remoção total das aristas (77\%). As sementes originárias do tratamento com aristas, arista totalmente removida e arista com remoção parcial 
apresentaram valores que não diferiram estatisticamente entre si, sendo que os tratamentos com aristas e com remoção parcial de aristas foram superiores aos tratamentos sem aristas. No que diz respeito a biomassa verde de plântula (BVP) e biomassa seca de plântulas (BSP) 0 tratamento correspondente às espigas completamente aristadas mostrou-se estatisticamente superior, não diferindo dos tratamentos com remoção parcial e total das aristas.

O tratamento correspondente ao trigo mútico apresentou os valores mais baixos em relação aos parâmetros de peso de biomassa de plântulas. Os resultados obtidos neste estudo estão em concordância com aqueles de MOTZO \& GIUNTA (2002) em que as aristas tiveram efeito positivo sobre o rendimento de grãos de trigo, sendo que esses autores efetuaram as avalições em trigo duro. A mesma tendência também foi observada por SUNESON et al. (1948) que estudaram linhagens de trigo aristado, mostrando que na grande maioria possui mais alto peso de grão do que as linhagens sem aristas (múticas).

De acordo com MAYDUP et al., (2010), devido a observações previas de maiores fotossínteses em trigos aristados, poderia se esperar que o peso seco das espigas e o índice de colheita fosse maior, fato que foi corroborado pelos resultados alcançados no presente trabalho.

TABELA 1- Média ( \pm desvio padrão) do Peso de Mil Sementes (PMS), Germinação, Biomassa Verde por Plântula (BVP), Biomassa Seca por Plântula (BSP). UNICRUZ, Cruz Alta, RS, 2015.

\begin{tabular}{ccccc}
\hline Tratamentos & PMS (g) & $\begin{array}{c}\text { Germinação } \\
(\%)\end{array}$ & BVP (g) & BSP (g) \\
\hline Sem aristas & $13,05 b^{*}$ & $68 b$ & $1,27 b$ & $0,16 \mathrm{c}$ \\
Com aristas & $20,1 \mathrm{a}$ & $84 \mathrm{a}$ & $1,95 \mathrm{a}$ & $0,26 \mathrm{a}$ \\
$\begin{array}{c}\text { Aristas totalmente } \\
\text { removidas }\end{array}$ & $16,4 \mathrm{~b}$ & $77 \mathrm{ab}$ & $1,47 \mathrm{ab}$ & $0,19 \mathrm{bc}$ \\
$\begin{array}{c}\text { Aristas com remoção } \\
\text { parcial }\end{array}$ & $18,3 \mathrm{ab}$ & $86 \mathrm{a}$ & $1,65 \mathrm{ab}$ & $0,21 \mathrm{ab}$ \\
Coeficiente de variação (\%) & 12,18 & 13,79 & 23,36 & 22,44 \\
\hline
\end{tabular}

*Médias seguidas por letras diferentes diferem estatisticamente pelo teste de Tukey a $5 \%$ de probabilidade de erro.

\section{CONCLUSÕES}

Nas condições em que foi realizado este estudo, pode-se concluir que genótipos de trigo aristados, sendo cultivados na região noroeste do Rio Grande do Sul, apresentaram peso de mil sementes superior aos genótipos de trigos não aristados ou com remoção das aristas. A germinação, biomassa verde de plântula e biomassa seca de plântula também avaliadas no estudo mostraram a mesma tendência.

\section{REFERÊNCIAS}

CALDEIRA, N., LIMA, A., SEKI, A., \& RUMJANEK, D. Diversidade de trigos, tipificação de farinhas e genotipagem. Biotecnologia e Desenvolvimento, São 
Paulo, v. 1, n. 1, p. 44-48, $2003 . \quad$ Disponível em:<http://www.biotecnologia.com.br/revista/bio16/16_trigo.pdf>

CONAB, Acomp. Safra Bras. Grãos, v. 1 - Safra 2013/14, n. 3 - Terceiro Levantamento. $\quad$ p.67-70, $2014 . \quad$ Disponível em:< Http://www.agricultura.gov.br/arq_editor/file/camaras_setoriais/Culturas_de_inverno/ 38RO/App_M ercado_Inverno.pdf> Acesso: 03 fev, 2015.

DOMICIANO, G.P.; RESENDE, R.S.; RODRIGUES, F.A.; DAMATTA, F.M. Alterações na fotossíntese de plantas infectadas por fitopatógenos. Revisão Anual de Patologia de Plantas, v.17, p.305-339, 2009.

FELICIO, J. C., CAMARGO, C., GERMANI, R., FREITAS, J., \& FERREIRA FILHO, A. W. P. Rendimento de grãos e qualidade tecnológica de genótipos de trigo em três zonas tritícolas do estado de São Paulo no Biênio 1994-95. Bragantia, Campinas, v. 59, n. 1, p. 59-68, 2000. Disponível em: <http://www.scielo.br/scielo.php?script=sci_arttext\&pid=S0006-

87052000000100010>. doi: http://dx.doi.org/10.1590/S0006-87052000000100010

GENEC, I. Physiological and morphological principles of grain yield cereals. C.U. Annal off Agricultural Faculty. 1977.

GRUNDBACHER, F. J. The physiological function of the cereal awn. Botanical Review, v. 29, n. 3, p. 366-381, 1963. Disponível em: <http://www.jstor.org/stable/4353672>

GUARIENTI, E. M., CIACCO, C. F., CUNHA, G. D., DUCA, L. J. D., \& CAMARGO, C. M. O. Avaliação do efeito de variáveis meteorológicas na qualidade industrial e no rendimento de grãos de trigo pelo emprego de análise de componentes principais. Ciência e Tecnologia de Alimentos, v.23, n.3, p. 500-510, 2003. Disponível em: <http://www.scielo.br/scielo.php?pid=S010120612003000300034\&script=sci_abstract\&tlng=pt> doi: $\quad 10.1590 /$ S010120612003000300034.

LÓPEZ-CASTAÑEDA, C.; MOLERO, G.; REYNOLDS, M. P. Genotypic variation in light interception and radiation use efficiency: A comparison of two different planting systems. In: Symposium. Proceedings of the 4th International Workshop of the Wheat Yield Consortium. México, DF-CIMMYT. p. 187-195, 2014.

MAHMOOD, N.; CHOWDHRY, M. A. Removal of green photosynthetic structures and their effects on some yield parameters in bread wheats. Wheat information service. 85: 14-20. 1997. YOKOHAMA, JAPÃO.

MAYDUP, M.L.; ANTONIETTA, M.; GRACIANO, C.; GUIAMET, J.J.; TAMBUSSI, E.A. The contribution of the awns of bread wheat (Triticum aestivum L.) to grain filling: Responses to water deficit and the effects of awns on ear temperature and hydraulic conductance. Field Crops Research, v. 167, p. 102-111, 2014. Disponível em: <http://www.sciencedirect.com/science/article/pii/S0378429014002159> doi: 10.1016/j.fcr.2014.07.012 
MAYDUP, M.L.; ANTONIETTA, M.; GUIAMET, J.J.; GRACIANO, C.; LÓPEZ, J.R.; TAMBUSSI, E.A. The contribution of ear photosynthesis to grain filling in bread wheat (Triticum aestivum L.). Field Crops Research, v. 119, n. 1, p. 48-58, 2010. Disponível <http://www.sciencedirect.com/science/article/pii/S0378429010001528> doi: 10.1016/j.fcr.2010.06.014

MILLER, E. C., \& GAUCH, H. G. A study of the morphological nature and physiological function of the awns in winter wheat. Kansas Agr. Exp. Sta. Bull. 57p. 1944.

MOTZO, R.; GIUNTA, F. Awnedness affects grain yield and kernel weight in nearisogenic lines of durum wheat. Australian Journal of Agricultural Research, v. 53, n. 12, p. 1285-1293, 2002. Disponível em: < http://www.publish.csiro.au/?paper=AR02008> doi: 10.1071/AR02008

REYNOLDS, M.; TUBEROSA, R. Translational research impacting on crop productivity in drought-prone environments. Current Opinion in Plant Biology, v. 11 , n. 2, p. 171-179, 2008. Disponível em: < http://www.sciencedirect.com/science/article/pii/S1369526608000332> doi: 10.1016/j.pbi.2008.02.005

RODRIGUES, O. Manejo de trigo: Bases ecofisiológicas. In: CUNHA, G. R.; BACALTCHUK, B. Tecnologia para produzir trigo no Rio Grande do Sul. Porto Alegre: Assembleia Legislativa do Rio Grande do Sul, 2000. p. 120-169. Série Culturas - Trigo.

SANCHEZ-BRAGADO, R.; MOLERO, G.; REYNOLDS, M.P. \& ARAUS J.L. Relative contribution of shoot and ear photosynthesis to grain filling in wheat under good agronomical conditions assessed by differential organ $\delta 13 \mathrm{C}$. Journal of Experimental Botany, v. 65 , n. 18, p. 5401-5413, 2014. Disponível em: < http://jxb.oxfordjournals.org/content/65/18/5401.abstract?ijkey=1443b35e9f13456124 51a531aa43710d8698d59a\&keytype2=tf_ipsecsha> doi: 10.1093/jxb/eru298

SCOTT, R. K.; DENNIS-JONES, R. The physiological background of barley. Journal of the National Institute of Agricultural Botany, Cambridge, v. 14, n. 1. p. 181187, 1976.

SILVA, J. A., CARVALHO, F., SILVA, S., BARBIERI, R., MARCHIORO, V., LORENCETTI, C., \& BENIN, G. Temperatura e seus efeitos na polinização para a obtenção de embriões haploides de trigo em cruzamento intergenérico. Revista Brasileira de Agrociência, Passo Fundo, v. 8, n. 2, p. 97-102, 2002.

SILVA, S. A., CARVALHO, F. D., NEDEL, J. L., CRUZ, P. J., PESKE, S. T., SIMIONI, D., \& CARGNIN, A. Enchimento de sementes em linhas quase-isogênicas de trigo com presença e ausência do caráter "stay-green". Pesquisa Agropecuária Brasileira, Brasília, v.38, n.5, p.613-618, 2003. Disponível em: <http://ainfo.cnptia.embrapa.br/digital/bitstream/AI-SEDE/24587/1/v38n5_613.pdf> 
SUNESON, C. A.; BAYLES, B. B.; FITIELD, G. C. Effects of awns on yield and market qualities of wheat. U.S. Deot Agric. Circ 783, 1948. Disponível em: $<$ https://archive.org/details/effectsofawnsony783sune>.

VALÉRIO, I. P.; CARVALHO, F. I. F.; OLIVEIRA, A. C.; BENIN, G.; MAIA, L. C.; SILVA, J. A. G.; SCHMIDT, D. M.; SILVEIRA, G. Fatores relacionados à produção e desenvolvimento de afilhos em trigo.Semina: Ciências Agrárias, Londrina, v. 30, p. 1207-1218, 2009. Suplemento 1.

VERVELDE, G.J. The agricultural value of awns in cereals. Neth. J. Agr. Sci. I-2. 1953. Amsterdam, the Netherlands.

WEYHRICH, R. A., CARVER, B. F., \& MARTIN, B. C. Photossintese and water-use efficiency off awned and awnletted near - isogenic lines off hard winter wheat. Crop Science v. 35, p. 172-176, 1995. Madison. 